\title{
FREE GLOBAL DEM: CONVERTING DSM TO DTM AND ITS APPLICATIONS
}

\author{
Atriyon Julzarika ${ }^{1,2 *}$, Harintaka $^{1}$ \\ ${ }^{1}$ Department of Geodesy, Universitas Gadjah Mada (UGM), Yogyakarta, Indonesia - harintaka@ugm.ac.id \\ ${ }^{2}$ Remote Sensing Applications Center, Indonesian National Institute of Aeronautics and Space (LAPAN) - \\ atriyon.julzarika@lapan.go.id
}

KEY WORDS: DSM, DTM, DEM integration, Rote islands

\begin{abstract}
:
DTM is a digital model that visualizes height topography. DTM can be used for various survey mapping applications. DTM can be derived from DSM. Currently DSM is widely available but the availability of DTM is still rare, especially in Indonesia. In this study, DSM was obtained from a combination of DSM X SAR, SRTM, and TanDEM-X with the integration method. This DSM integration made height error correction and height reference field to the EGM 2008. This DSM integration has fulfilled the tolerance of vertical accuracy in $1.96 \sigma(95 \%)$. This study aims to convert DSM to DTM and discuss some of the DTM applications. The study area of this study is Rote Islands (north and east side), especially in the Dead Sea Lake Area which includes Lake Oemasapoka to Oesu Island. DSM can be converted into DTM by considering several things, namely the canopy tilt angle to topography, the height of the vegetation approach, and the radius defined around the canopy. One way to get this parameter is to make contours on the vegetation in the DSM. After conversion of DSM to DTM, DTM is obtained at ground level. The DTM that has been produced needs to be done a height difference test and the making of longitudinal profile. This longitudinal profile will visualize the conditions of DSM and DTM so that the vegetation height will appear along the profile. The resulting DTM can be used for several applications such as topographic contours, watersheds, water levels, flow accumulation, slope, slope direction, and others.
\end{abstract}

\section{INTRODUCTION}

\subsection{Background}

The development digital technology of terrestrial, aerial and satellite has been significant. One of these developments is in measuring height differences. One way to visualize the height difference is using Digital Elevation Model (DEM).

DEM is a generic term for topographic digital covering data in all its forms as well as the method for interpreting the implication of elevations between observations (Maune et al., 2001; Maune \& Nayegandhi, 2018). Digital surface model (DSM) is a depicting model of the top of reflective surfaces, such as buildings and vegetation (Maune et al., 2001; Maune \& Nayegandhi, 2018). DTMs as digital representations of topographic surfaces, digital models of gradient $(G)$, aspect (A), horizontal $(\mathrm{Kh})$ and vertical $(\mathrm{Kv})$ land surface curvatures as well as other topographic attributes ( $\mathrm{Li}$ et al., 2005). Digital terrain models (DTM) are a synonym for bare-earth DEM (Maune et al., 2001). There are several methods of making DEM, namely Triangular Irregular Network (TIN), stereo, interferometry, LIDAR, videogrammetry, combining DEM (fusion and integration).

Related research to DSM has long been carried out, but the application of converting DSM to DTM is still rare. One study that has been able to transform DSM into DTM is (Gallant, Read, and Dowling 2012). Other studies related to convert DSM to DTM are (Fukuda, Tokuhara, and Yabuki 2016). They made 3D models like buildings with physical dynamic model systems. Then (Naidoo et al. 2016) also uses band L to calculate the tree canopy. This will help in making DSM and its converting into DTM. (Moudrý et al. 2018) also deals with how to eliminate height errors and converting DSM to DTM. They are implementing global DEM in ecological modeling. Correlations of DSM and DTM have also been studied by (Shen et al. 2018) who utilize ICESat / GLAS data in mapping aboveground biomass. Likewise with (Rogers et al. 2018) who tried to find a correlation of converting DSM and DTM. They discussed that associated salt swamp vegetation tends to increase vertical uncertainty in light detection and sort elevation data originating from lidar, often causing data to be ineffective for analysis of topographic features governing tidal inundation or vegetation zoning. (Zhang et al. 2016) tried the low resolution DSM extraction research with a semi-global filter. This will be useful in the correlation in decreasing DSM to DTM.

Most DEM in Indonesia are still in the form of DSM. It is still rare in the form of DTM. DTM needs in Indonesia are very high, especially in various survey mapping, disaster mitigation and environmental applications. In addition to the many potentials available, the free DSM can be used to extract lowcost DTM that meet certain mapping scales. Currently combining DEM is available with the fusion method in Indonesia. This DEM fusion is still in the form of DSM so it is not optimal for various applications. This study aims to convert DSM to DTM and discuss some of the DTM applications.

\section{METHOD}

The method in this paper discusses data, tree offset methods and DEM integration, and research methodology. The data includes X SAR, SRTM, and TanDEM-X.

Corresponding author 


\subsection{SAR, SRTM, and TANDEM X}

This research use X SAR, SRTM, and TanDEM X data. All data are free global DEM. The mission of Topography Shuttle Radar (SRTM, DTS-99) from 11 to 22 February 2000 is a USGerman-Italian effort to produce the first global DEM (DLR, 2019). The German Aerospace Center (DLR) and the Italian Space Agency (ASI) complete NASA/JPL C-band Synthetic Aperture Radar (SAR) loads with additional X-SAR instruments. SRTM X-SAR DEM is generated on the DLR from this instrument data using radar interferometry techniques. Data was obtained simultaneously from the space shuttle Endeavor using two SAR antennas, one inside the Space Shuttle cargo space, the other at the end of the $60 \mathrm{~m}$ extension pole.

In this study using X SAR, SRTM, and TanDEM-X data. Shuttle Radar Topographic Mission (SRTM, DTS-99) from 11 to 22 February 2000 is a US-German-Italian effort to produce the first global DEM (DLR, 2019). The German Aerospace Center (DLR) and the Italian Space Agency (ASI) complete NASA/C-band Synthetic Aperture Radar (SAR) loads with additional X-SAR instruments. SRTM X SAR is generated on the DLR from this data instrument using radar interferometry techniques. (DLR, 2019)

TanDEM-X is an Earth observation radar mission that consists of a SAR interferometer built by two almost identical satellites flying in close formation. TanDEM-X have the absolute height error is with about $1 \mathrm{~m}$ an order of magnitude below the $10 \mathrm{~m}$ requirement. The TanDEM-X $90 \mathrm{~m}$ DEM is a product variant of the global DEM (2010-2015). It has spatial resolution 3 arcseconds (90m at the equator). It covers all Earth's landmasses from north pole to south pole. (DLR, 2019)

\subsection{Tree Offset and DEM Integration}

The tree offset was estimated near every patch edge by least squares estimation based on a model of local height variations (Gallant et al., 2012). Subtraction of offset from DSM to produce DTM. The interpolated tree offset is multiplied by the smoothed tree cover map to produce an estimate of the tree offset that can be subtracted from the DSM to produce the bareearth DEM.

Estimates of tree offsets depend on accurately identifying high objects in topography that are not covered by trees. DSM registration and land cover will produce lower offset tree estimates. Offset that experiences height error needs to be removed to be effective in DSM conversion to DTM (Gallant et al., 2012).

According to (Gallant et al., 2012), the response of the DSM SRTM to changes in tree cover is not sharp but transitions smoothly over a distance of 3-4 grid cells (around $100 \mathrm{~m}$ ). This smooth transition must be accounted for in the correction of offsets to avoid artefacts around tree cover patches. The artefact is similar with height errors in DEM. Height errors correction is needed to remove the height errors. The correct estimation of tree offset relies on accurately identifying the location of the transition from non-tree-covered to tree-covered terrain (Gallant et al., 2012).

Combining DEM data is done using two methods, namely DEM integration and DEM fusion. Some modifications were made such as: height error correction, making Height Error Maps (HEM), adding weight, detection and error removal methods (making voids), and CoKriging interpolation methods performed (Julzarika, 2015a). The concept of DEM integration and DEM fusion refers to concepts developed in previous studies (Hoja and d'Angelo, 2010; Hoja et al., 2006; Julzarika, 2015b). According to (Hoja et al., 2006; Trisakti \& Julzarika 2011), the best method with higher accuracy for combining DEM is integration. The fastest method is fusion but less accuracy for combining DEM.

\subsection{Methodology}

This study uses the methodology shown in Figure 1. X SAR, SRTM, and TanDEM-X data are used as input data. These three data were carried out by DEM integration after being free from height errors and using the same height reference fields. In this study using EGM2008. The location of the study was carried out on Rote Islands, East Nusa Tenggara, Indonesia.

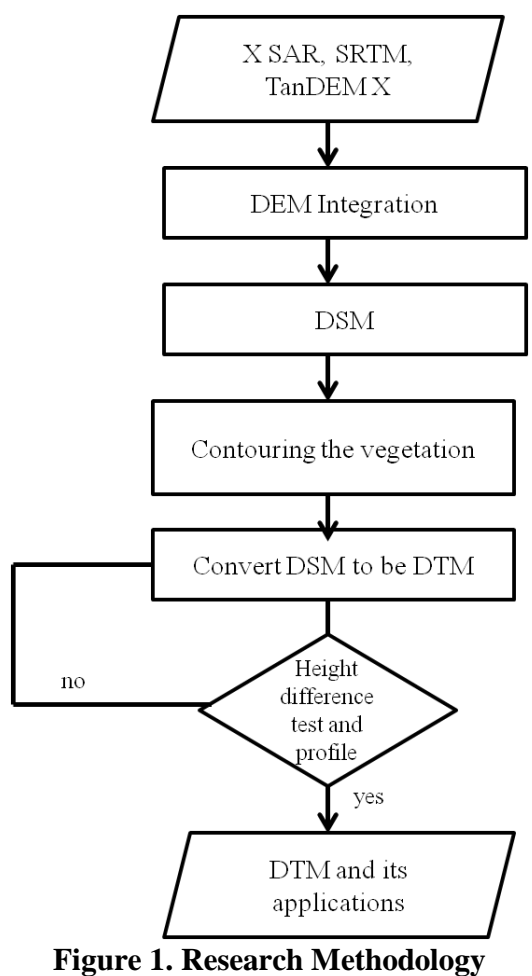

If DEM integration has been carried out, then DEM integration will be obtained. This DEM has at least a height error because the three DEMs before integration are carried out with height error correction. This DEM integration, here in after referred to as DSM, is ready to be used for the converting DSM to DTM. The next method is to contour the vegetation on DSM. This vegetation contour is useful in determining the shape, pattern, and texture of vegetation and topography. This is useful in knowing the slope angle of the vegetation canopy against topography. It can also be used in estimating the initial height of vegetation in the study area. Then it can also be used to estimate the radius of DSM against the vegetation used. After obtaining all parameters, DSM is converted into DTM. Contour making on DTM is needed to see visually about free height error on topography. Height difference test needs to be done because it is an indication that the resulting DTM is a minimum height error and fulfills tolerance $1.96 \sigma$ (ASPRS, 2014). In addition to the height difference test, longitudinal profile is also needed to see the visual appearance of the DTM against DSM. DTM obtained can be used for watershed applications, water level, slope, slope direction and flow accumulation. 


\section{RESULT AND DISCUSSION}

The results discussed about DSM, DTM, vegetation height, applications, height difference test, and longitudinal profile.

\subsection{DSM, DTM, and vegetation height}

The results integration of TanDEM-X with X SAR and SRTM are still in the form of DSM. This integration uses the height reference field EGM 2008. There is a slight difference in band $\mathrm{X}$ on TanDEM-X and X SAR with band $\mathrm{C}$ on SRTM. In addition there is also a difference in the acquisition of $X$ SAR and SRTM with TanDEM-X. X SAR and SRTM in 2000, while TanDEM $X$ is around 2010-2015. Generally these differences have an impact on determining vegetation height. However, this height difference is not significant in this region because it is dominated by steppes and there are few primary and secondary forests. Based on the results of a survey in the field, the addition of forest height in this area is relatively slow so that high changes can be ignored. DSM results from TanDEM-X integration with SRTM and X SAR can be seen in the Figure 2.

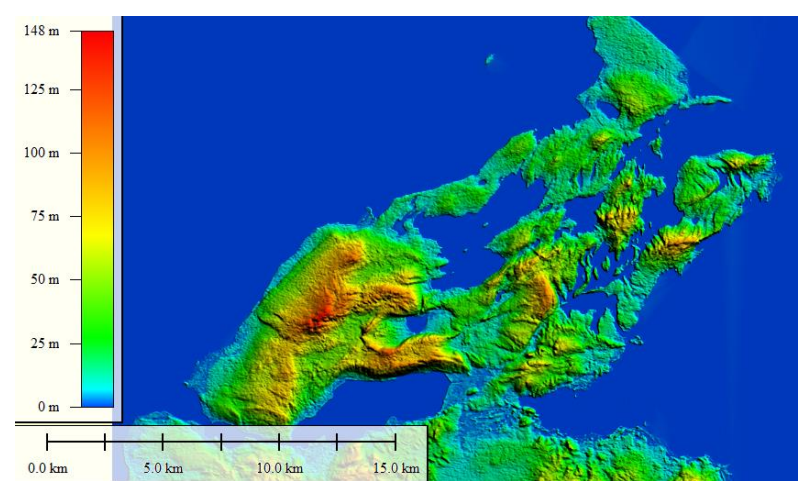

Figure 2. DSM of Rote islands

DSM in the region has height between 0-148 $\mathrm{m}$. The vegetation of this region is generally located at $10-40 \mathrm{~m}$ elevation. In addition, it is also dominated by lakes with elevation of 5-60 m above sea level. Making the contours in DSM are needed to determine the conditions and texture and distribution patterns of vegetation and lies in a particular topography. In addition, this contouring the vegetation height makes it easy in converting DSM to DTM. Based on the vegetation contour, it can be estimated the value of the initial approach to vegetation height, the slope of the vegetation canopy, and the estimated filter radius of the vegetation canopy. In this region, the slope of the vegetation canopy against the topography is worth $60 \%$. This generally occurs in areas with forest cover. In areas with coverings of steppe savannahs, the slope of the vegetation canopy against the topography is between $5-20 \%$, depending on the contour pattern made. The vegetation contour on the DSM integration of TanDEM-X with X SAR and SRTM can be seen in Figure 3.

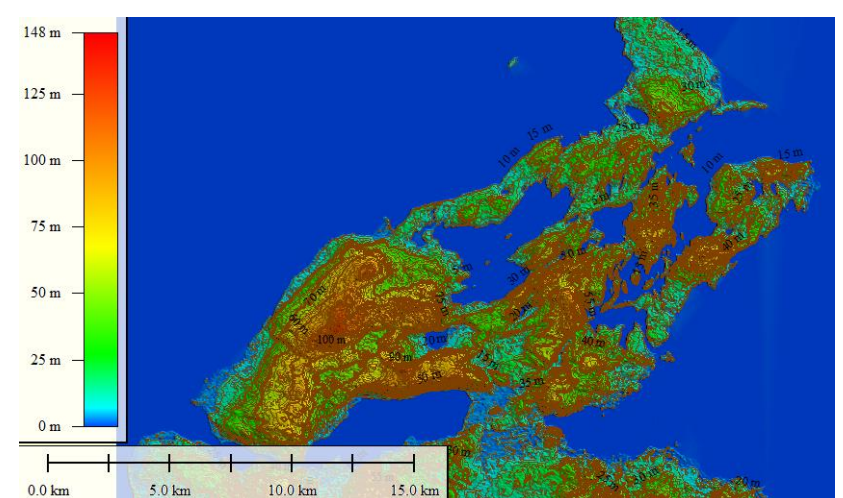

Figure 3. contouring in vegetation height of DSM

The next process is to convert DSM to DTM in accordance with previously defined parameters. The results of conversion to DTM depend on the quality produced of vegetation height. The results of converting DSM to DTM can be seen in Figure 4.

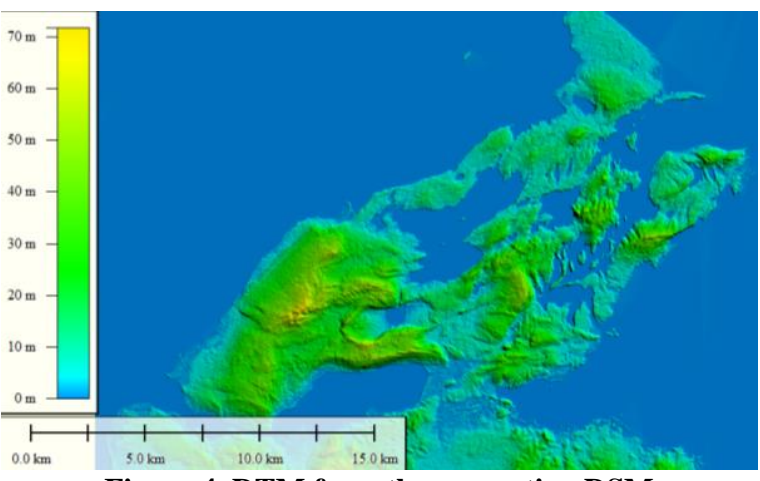

Figure 4. DTM from the converting DSM

The height value on the DTM is $0-70 \mathrm{~m}$. Height values on DTM are dominated by elevations of $10-40 \mathrm{~m}$. After obtaining the DTM, topographic contours are made. This aims to determine the pattern and shape of the topography of the study area. This area is dominated by low and medium land. DTM results and topographic contour extraction can be seen in Figure 5.

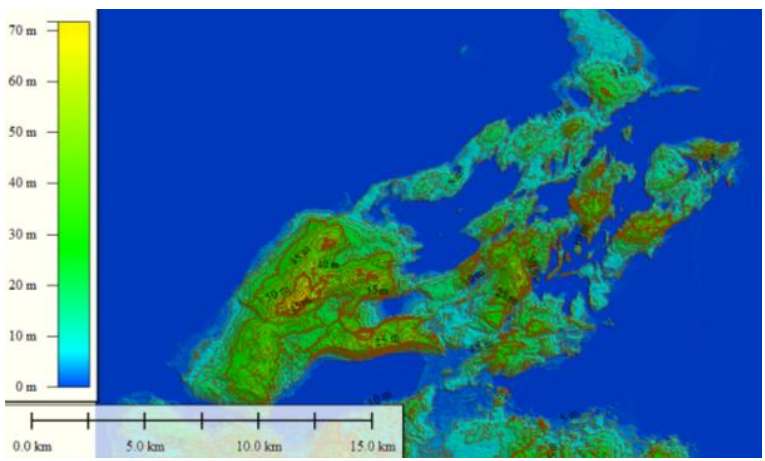

Figure 5. topographic contour from DTM

After obtaining DSM and DTM, it is possible to calculate the estimated vegetation height. DSM is deducted by DTM to obtain vegetation height (nDSM). The vegetation height in this region is $0-76 \mathrm{~m}$. The value of the $50-76 \mathrm{~m}$ vegetation is located in a forest dominated area. The value of $0-10 \mathrm{~m}$ vegetation is located in a lowland dominated by steppe savanna and low vegetation. This vegetation height can be seen in Figure 6 . 


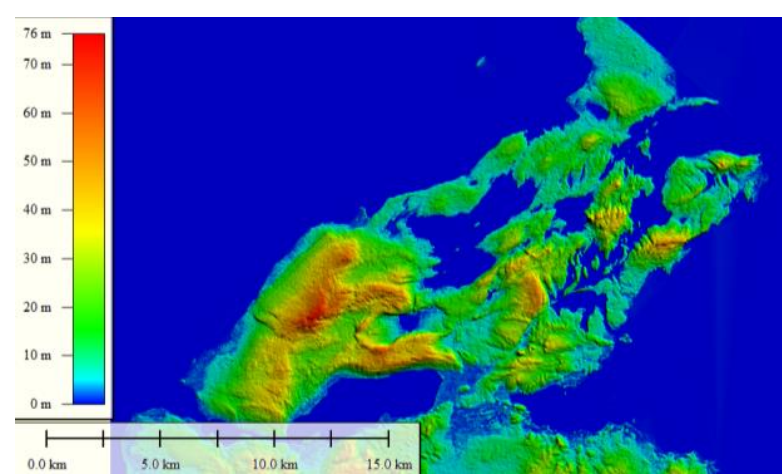

Figure 6. vegetation height from DSM and DTM

\subsection{DTM applications}

DTM that has been made can be used for various applications such as watershed, water level, flow accumulation, slope, slope direction, and others. In making the watershed applications, the DTM used can separate watershed to the sub-watershed level. The results of making watershed are in Figure 7.

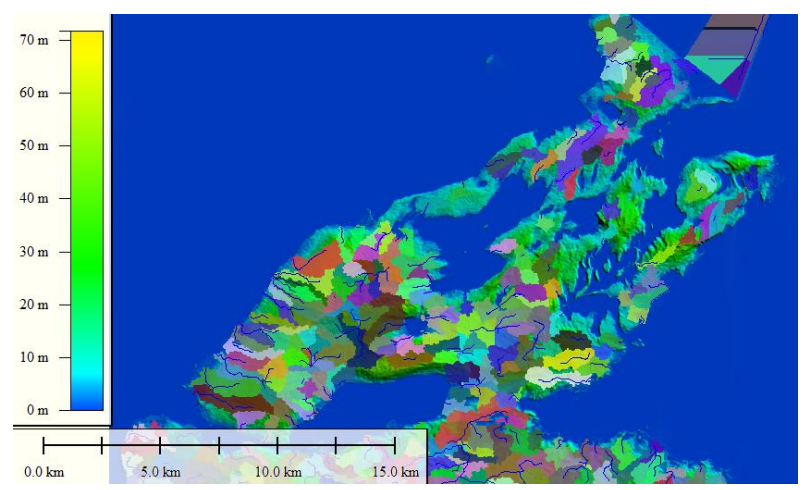

Figure 7. watershed from DTM

In water level applications, DTM is used to distinguish land and water. This water level can be used to determine shorelines and lake boundaries. The boundary between land and water lies on the slope of $0^{0}$. This water level result can be seen in Figure 8 .

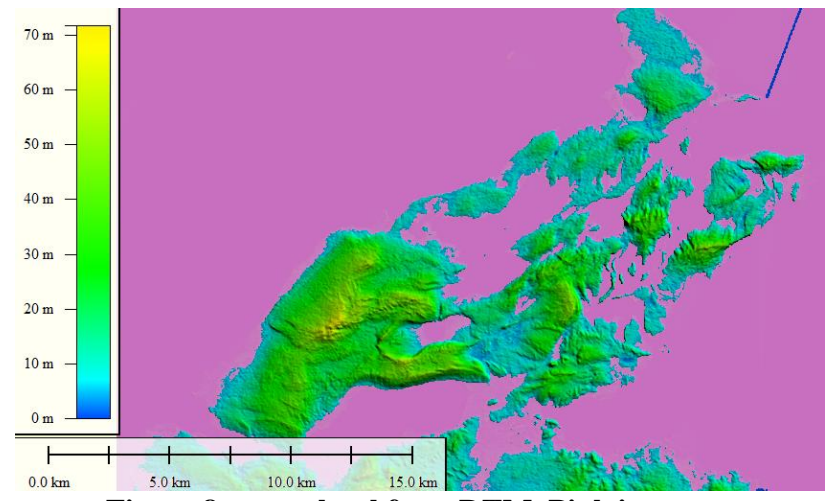

Figure 8. water level from DTM. Pink is water.

Flow accumulation application, the DTM used produces a higher order of surface flow or high surface flow detail. The flow accumulation extraction method is the steepest slope. This method takes into account the slope and height difference. Figure 9 is flow accumulation.

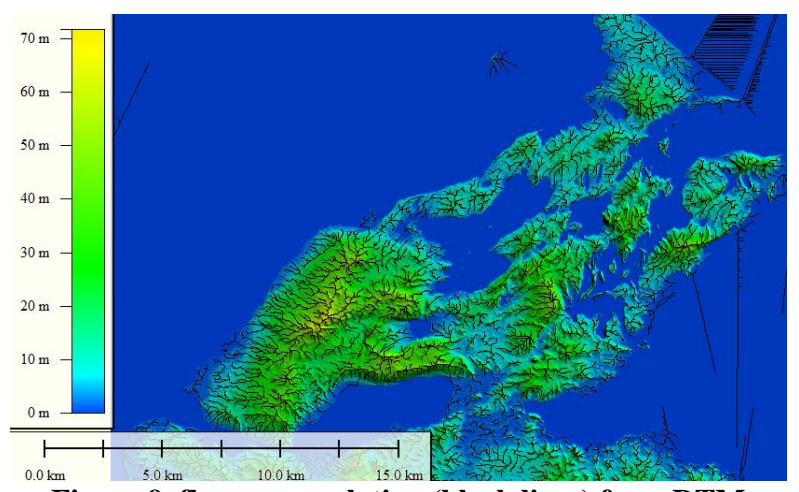

Figure 9. flow accumulation (black lines) from DTM

DTM can also be used to make slopes. The slope in the Rote islands has a low slope, which is $0-15^{0}$. This area slope can be seen in Figure 10.

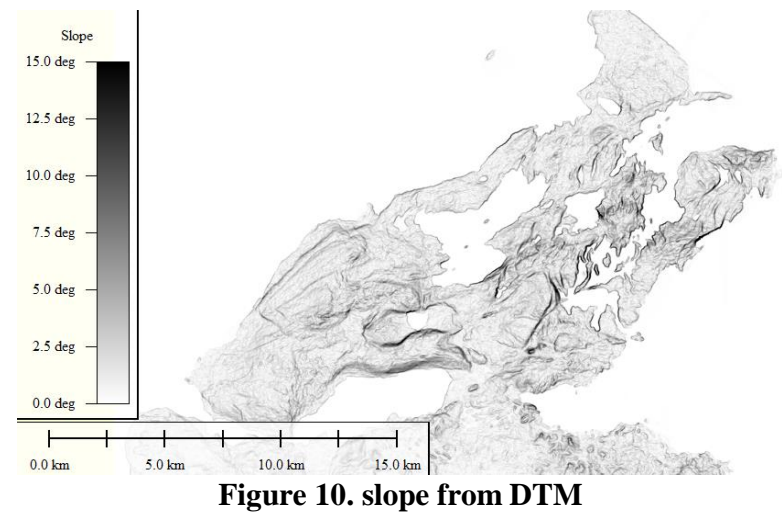

After the slope is obtained, then Aspect / Slope direction can be made. This direction of slope direction ranges from $0-360^{\circ}$. Slope direction is in Figure 11.

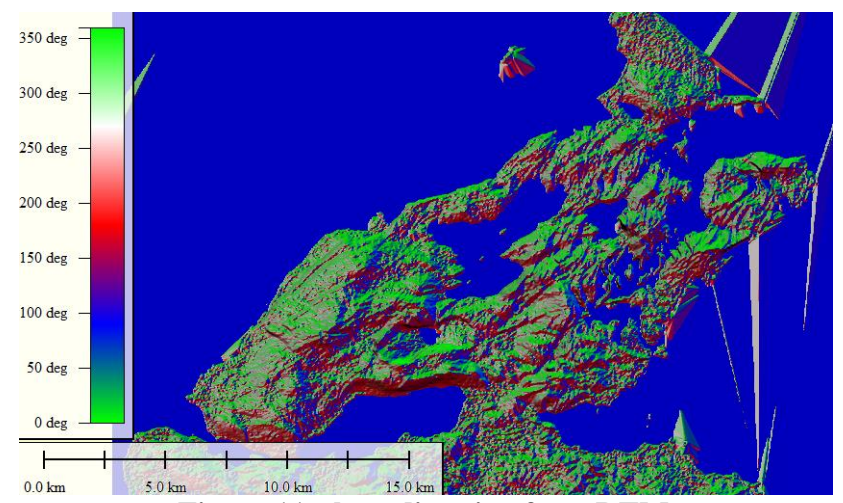

Figure 11. slope direction from DTM

\subsection{Height difference test and longitudinal profile}

Height difference test is done by making closed polygons. Then the sum of the height differences between the points of the polygon is summed, the total height difference in this region is $\sim 0 \mathrm{~m}$. This indicates that the DTM region is free blunder. The closed polygon created can be seen in Figure 12. 


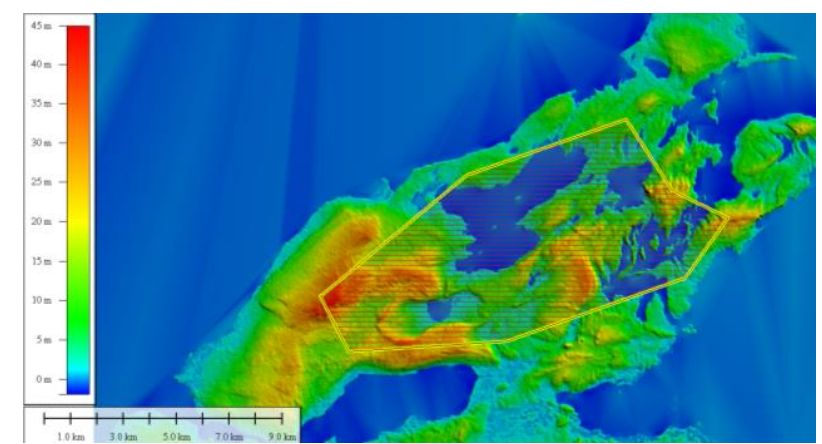

Figure 12. closed polygon for height difference test

Making this profile is one test to determine the profile pattern of a DEM transversely and extensively. In this paper what is done is making a longitudinal profile. There are 2 longitudinal profiles made in this paper. The longitudinal profile (1) is made from the southern side of the dead sea lake area, then passes the Lake Oemasapoka to the north and east of the island of Rote. The longitudinal profile (2) is made from the west side past the Lake Oendui to the east of the Rote dead sea lake area and ends in Mulut Seribu and Oesu island. Longitudinal profiles (1) and (2) can be seen in Figure 13.

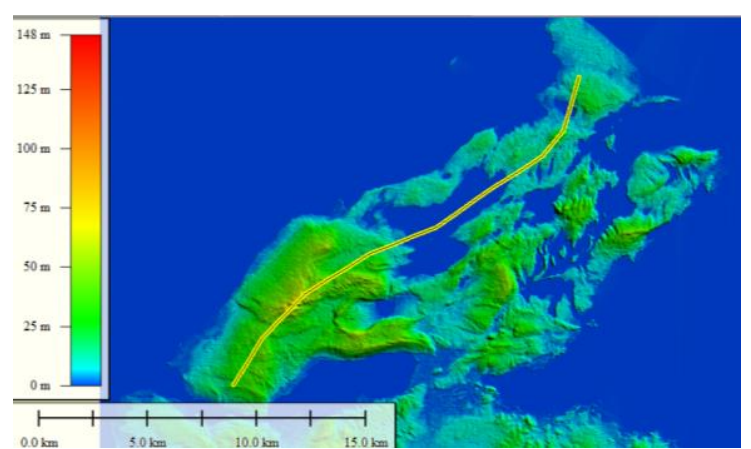

Figure 13. the longitudinal profile (1) from DTM.

In the longitudinal profile (1) a DSM-DTM graph is obtained, see Figure 14. The DSM (red) and DTM (blue lines) charts in the elongated profile area (1). On the left side of the graph can be seen higher vegetation height when passing through the forest land cover. Vegetation height is $25-70 \mathrm{~m}$. On the middle side of the graph the DSM value coincides with DTM. This area is Oemasapoka Lake. Then on the right side of the graph there is a high but not large difference. This region is low vegetation located in the steppe savanna. On the right side of the graph there is also Lake Oeapa and the condition of DSM coincides with DTM.

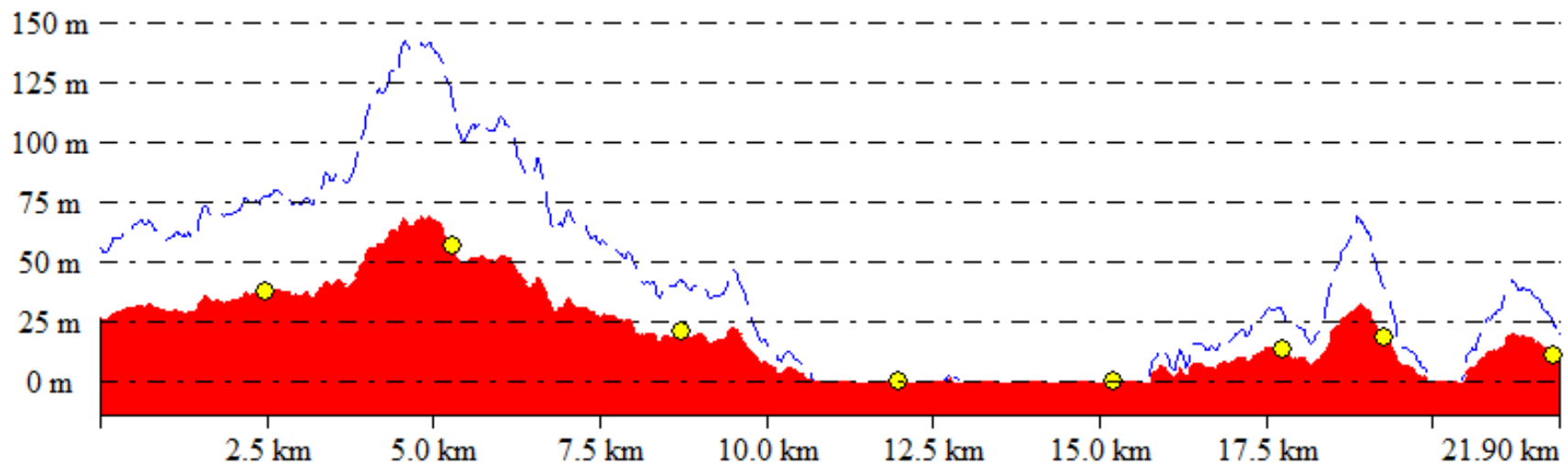

DSM: blue line, DTM: red line

Figure 14. the graph of longitudinal profile (1)

In a longitudinal profile (2) there is a relatively diverse vegetation height, see Figure 15. The DSM (red) and DTM (blue lines) charts in the elongated profile area (2). The lefthand side of the graph is dominated by land cover of forest with height difference 25-50 m, see Figure 16. In addition, in this region there are also steppe savanna with relatively small height difference of $0-10 \mathrm{~m}$. In the middle region the graph is dominated by low vegetation and steppe savanna. The center of the graph is the area of a thousand Rote mouths. In this region, many sea areas are located between low hills. On right side of the graph is Oesu island. In this region it has vegetation (forest) and it is located relatively in high topography. The vegetation height in this area is $40-60 \mathrm{~m}$.

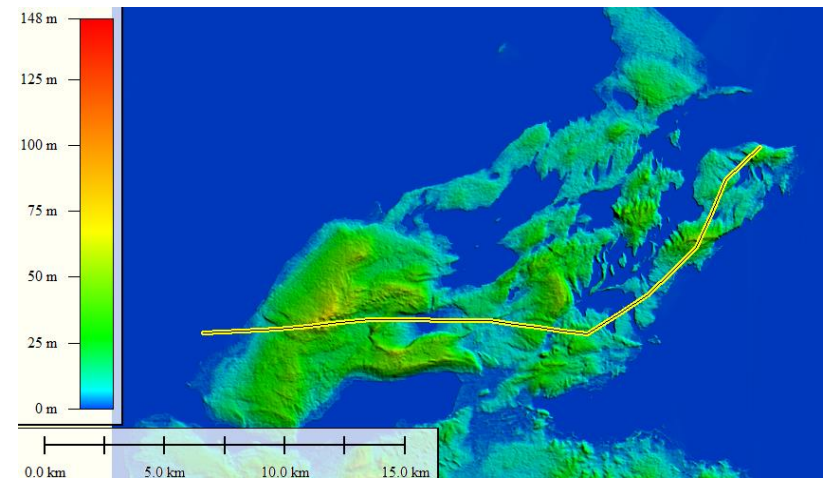

Figure 15. the longitudinal profile (2) from DTM. 


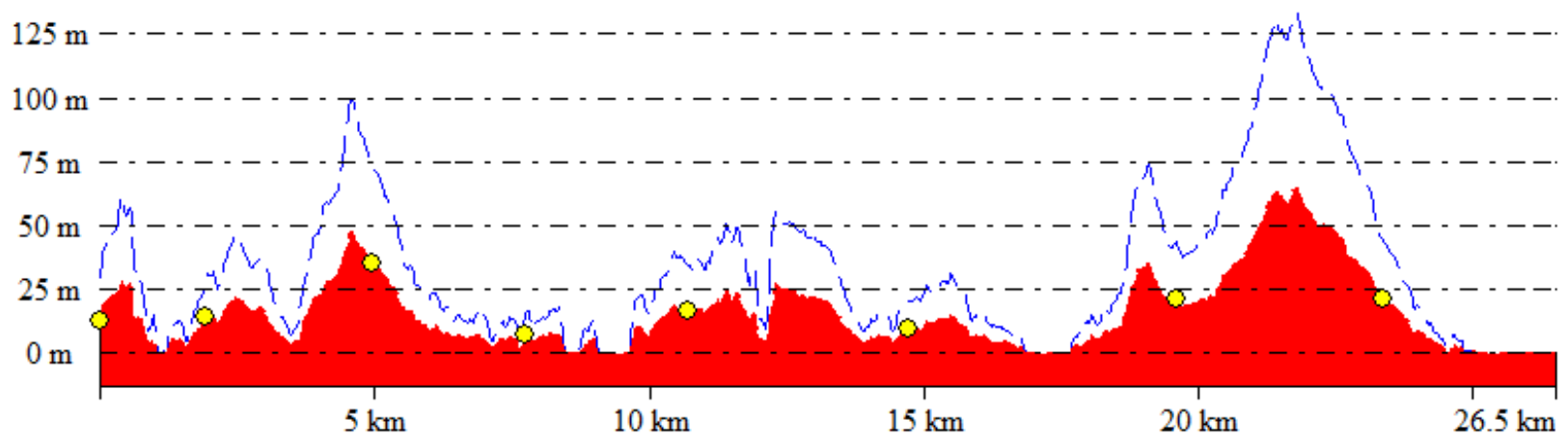

DSM: blue line, DTM: red line

Figure 16. the graph of longitudinal profile (2)

Longitudinal profiles can be used to calculate volume. Simulation of calculating the volume of DSM with DTM in a longitudinal profile (1) results in the form of cut volume: 158,996 cubic meters, cut surface area: $0.03184 \mathrm{sq} \mathrm{km}$, fill volume: $267,220.02$ cubic meters, and fill surface area: $0.063 \mathrm{sq}$ $\mathrm{km}$. Simulation of calculated volumes of DSM with DTM in longitudinal profiles (2) obtained results of cut volume: $547,528.46$ cubic meters, cut surface area: $0.04723 \mathrm{sq} \mathrm{km}$, fill volume: $646,553.04$ cubic meters, and fill surface area: 0.0855 sq $\mathrm{km}$.

\section{CONCLUSION}

This study concludes that DTM can be made from DSM conversion based on slope of vegetation canopy parameters on topography, prediction of vegetation height, and radius. These parameters can be approached by analyzing the contours of the vegetation height that have been made. DSM used is an integration of X SAR, SRTM, and TanDEM-X. The DSM integration was first made height error correction and likened to height reference field in EGM 2008. This DTM can be used for applications for making topographic contours, watersheds, water levels, flow accumulation, slope, slope direction, and so on. The DTM that is made must be carried out a height difference test and longitudinal profile.

\section{ACKNOWLEDGEMENTS}

Thanks to the Universitas Gadjah Mada and Indonesian National Institute of Aeronautics and Space for supporting this research. In addition, thanks to free online data of X SAR, SRTM, and TanDEM-X from DLR and NASA. Thank for others people who have supporting this research. Both authors are the main contributors to this paper.

\section{REFERENCES}

ASPRS, 2014. ASPRS Accuracy Standard for Digital Geospatial Data. ASPRS. United States of America.

DLR, 2019. SRTM-DLR. German Aerospace Center. accessed in May $1^{\text {st }} 2019$. Germany.

Fukuda, Tomohiro, Toshiki Tokuhara, and Nobuyoshi Yabuki. 2016. "A Dynamic Physical Model Based on a 3D Digital Model for Architectural Rapid Prototyping." Automation in Construction 72: 9-17. http://dx.doi.org/10.1016/j.autcon.2016.07.002.
Gallant, J. C., a. M. Read, and T. I. Dowling. 2012. "Removal of Tree Offsets From Srtm and Other Digital Surface Models." ISPRS - International Archives of the Photogrammetry, Remote Sensing and Spatial Information Sciences XXXIXB4(September): 275-80.

Hoja D., Reinartz P. \& Schroeder M., 2006. Comparison Of Dem Generation And Combination Methods Using High Resolution Optical Stereo Imagery And Interferometric SAR Data, International Archives of the Photogrammetry, Remote Sensing and Spatial Information Science, Volume XXXVI, Part 1, Paris, France.

Hoja D. \& d'Angelo P, 2010. Analysis Of Dem Combination Methods Using High Resolution Optical Stereo Imagery And Interferometric SAR Data, International Archives of the Photogrammetry, Remote Sensing and Spatial Information Science, Volume XXXVIII, Part 1, Calgary, Canada.

Julzarika, A. 2015a. Integrasi model tinggi X SAR, XRTM C, Aster GDEM, dan ALOS PALSAR. Tesis. Teknik Geomatika, Universitas Gadjah Mada.

Julzarika, A., 2015b. Height Model Integration Using Alos PALSAR, X SAR, SRTM C, and ICESAT/GLAS. International Jornal of Remote Sensing and Earth Sciences. DOI: http://dx.doi.org/10.30536/j.ijreses.2015.v12.a2691.

Li, Z., Zhu, Q., \& Gold, C., 2005. Digital Terrain Modeling Principles and Methodology. CRC Press. Florida. USA.

Maune, D.F., et al., 2001. Digital Elevation Model-DEM Users Manual. Digital Elevation Model Technologies and Applications. 1st edition. ASPRS.

Maune. D.F.\& Nayegandhi, A., 2018. Digital Elevation ModelDEM Users Manual. Digital Elevation Model Technologies and Applications. 3rd edition. ASPRS.

Moudrý, Vítězslav et al. 2018. "On the Use of Global DEMs in Ecological Modelling and the Accuracy of New Bare-Earth DEMs." Ecological Modelling 383(January): 3-9.

Naidoo, Laven et al. 2016. "L-Band Synthetic Aperture Radar Imagery Performs Better than Optical Datasets at Retrieving Woody Fractional Cover in Deciduous, Dry Savannahs." International Journal of Applied Earth Observation and 
The International Archives of the Photogrammetry, Remote Sensing and Spatial Information Sciences, Volume XLII-4/W16, 2019 6th International Conference on Geomatics and Geospatial Technology (GGT 2019), 1-3 October 2019, Kuala Lumpur, Malaysia $\begin{array}{lcc}\text { Geoinformation } & 52: & 54-64 . \\ \text { http://dx.doi.org/10.1016/j.jag.2016.05.006. }\end{array}$

Rogers, Jeffrey N., Christopher E. Parrish, Larry G. Ward, and David M. Burdick. 2018. "Improving Salt Marsh Digital Elevation Model Accuracy with Full-Waveform Lidar and Nonparametric Predictive Modeling." Estuarine, Coastal and Shelf Science 202: 193-211. https://doi.org/10.1016/j.ecss.2017.11.034.

Shen, Wenjuan et al. 2018. "Annual Forest Aboveground Biomass Changes Mapped Using ICESat/GLAS Measurements, Historical Inventory Data, and Time-Series Optical and Radar Imagery for Guangdong Province, China." Agricultural and $\begin{array}{lll}\text { Forest } & \text { Meteorology 23-38. }\end{array}$ https://doi.org/10.1016/j.agrformet.2018.04.005.

Trisakti \& Julzarika, 2011. DEM Generation from Stereo ALOS Prism and Its Quality Improvement. International Journal of Remote Sensing and Earth Sciences Vol. 8: 41-48. Indonesia.

Zhang, Yanfeng, Yongjun Zhang, Yi Zhang, and Xin Li. 2016. "Automatic Extraction of DTM from Low Resolution DSM by Twosteps Semi-Global Filtering." ISPRS Annals of the Photogrammetry, Remote Sensing and Spatial Information Sciences 3(July): 249-55. 